\title{
REFLEXÕES SOBRE A ÉTICA NO QUOTIDIANO DA PROFISSÃO
}

\section{Maria Olívia Dias*}

A ética é nas palavras de Megale o que de mais justo existe. Estas palavras, que são sem dúvida muito fortes, pretendem afirmar dentro do possivel, tudo aquilo que move a dinâmica deste trabalho. Com efeito, tendo o artigo por tema "Reflexões sobre a ética no quotidiano da profissão", a primeira questão que importa saber é naturalmente o que é a ética, o que é a profissão, para num passo seguinte se demonstrar por que formas poderá a ética influenciar a conduta do profissional, quais as causas e consequências das responsabilidades éticas na profissão. Não se pretende de forma alguma fazer aqui algum tipo de juizos de valor, não é da nossa competência, mas caracterizar uma realidade que pode ser controversa e até por vezes dramática para a consciência das pessoas. Cada vez mais as realidades complexas da sociedade, em geral, e da profissão em particular, interagem nos comportamentos dos profissionais. Quer isto dizer que do nosso ponto de vista vale a pena revisitar algumas ideias que possam contribuir não só para identificar alguns indicadores para a reflexão, mas também para que permitam lançar pistas susceptiveis de serem continuadas a aprofundar no futuro.

Palavras-chave: Ética, profissão, conduta humana, responsabilidade, comportamento profissional.

According to Megale ethics is the fairest thing on earth. This is a strong idea that is aimed at describing, as much as possible, this paper's dynamics. Bearing in mind its title, it is important to know what ethics and profession are in order to show in what ways ethics may influence the professional's behaviour, what causes and consequences derive from ethical responsibilities in professions. The aim of this paper is not to make judgements, but to characterize a reality that can be controversial and even dramatic to people's consciousness. Complex realities from society, in general, and from

\footnotetext{
* Instituto Universitário de Desenvolvimento e Promoção Social do Pólo de Viseu da Universidade Católica Portuguesa
} 
profession, in particular, interact more and more with the behaviours of professionals. This means that, from our point of view, it is important to revisit some ideas that can identify some indicators for the reflection as well as allow us to launch some hints that may be studied deeply in the future.

Key words: Ethics, profession, human behaviour, responsibility, professional behaviour.

\section{INTRODUÇÃO}

A publicação deste artigo sobre a ética no quotidiano da profissão responde a uma necessidade sentida, pela autora, por duas razões. A primeira, diz respeito ao desenvolvimento explosivo acerca do debate ético em torno das e nas organizações em geral ${ }^{1}$ e, nalgumas profissões em particular, umas mais preocupantes outras mais geradoras de esperança.

A segunda razão é que em todas as escolas onde se formam profissionais é abordada com maior ou menor desenvolvimento a ética profissional, pondo a ênfase nas situações concretas da actividade específica, nas diversas áreas, sendo um bem auxiliar das atitudes e comportamentos no exercício profissional a bem da dignidade da pessoa humana.

É sabido que a discussão feita em torno do tema sobre a ética, nos mais diversos tipos de profissão, tem-se orientado, quer queiramos quer não, para a qualidade de vida enquanto pessoas, mas também, enquanto profissionais, com repercussões no quotidiano subjectivo das organizações e objectivo das profissões.

Neste sentido, o principal interesse reside na análise de alguns aspectos que se pensa serem significativos, dando especial ênfase à ética profissional e à importância que esta questão assume na construção de atitudes e comportamentos profissionais das pessoas, às quais hoje tanto se presta atenção.

É assim que Argandoña Rámiz (1994:59) concebe a questão da ética como sendo um fenómeno que parece estar na moda da política, da economia, da empresa, da profissão, destacando que a ética está na moda pela falta de ética que observamos nestes campos. $\mathrm{O}$ autor dá conta que produzir, competir e superar um mercado corrupto, com trabalhadores, competidores, directores, lutando com imoralidade, com vícios, não é tarefa fácil. Também Moreira (1996: 289) põe em destaque a importância que a ética tem na sociedade moderna e progressista.

Por isso, não surpreende que atitudes e comportamentos antiéticos ponham em jogo não só a qualidade, mas também uma sobrevivência sem 
moral, sem ética, sem valores, contribuindo para a instabilidade profissional e social.

Não é por acaso que as grandes épocas de reflexão sobre a ética foram as grandes épocas de transição, em que se verificaram também a corrupção e a imoralidade. De novo, actualmente, volta-se a falar em todos os recônditos do mundo profissional da ética, para se encontrarem normas que inspirem o comportamento do ser humano, em geral na sociedade e em particular na organização e na profissão que exerce.

Não admira que a construção de uma ética na profissão envolva não só o trabalhador, a empresa, mas também a sociedade no seu conjunto. Para tal é necessário inovar através de políticas que envolvam e confiram importância a cada elemento, a cada pessoa, a cada trabalhador e ao seu contributo para um objectivo pessoal mas também comum. De pouco servirão grandes estratégias, se a colectividade não sentir uma consistência ética e moral nos procedimentos e comportamentos de cada indivíduo e sobretudo daqueles que têm maior responsabilidade face às funções e papéis que lhe são atribuídos.

Independentemente daquilo que se possa pensar quanto à vivência da ética, todos temos de reconhecer que qualquer profissional que considere os princípios éticos como o motor das suas escolhas, das suas acções e do seu agir, os resultados adquirem vivências que moldam não só o comportamento profissional, mas também conferem um modo de estar, que lhe proporciona uma forma diferente de entender o ser humano, alcançando uma salutar relação de grande qualidade não apenas técnica, mas também humana. Esta realidade assegura-lhe um conjunto de sinergias, e êxitos, que o levam a adquirir grande prazer naquilo que faz. Esta condição estende-se ao indivíduo, ao grupo profissional a que pertence, à empresa, ao bem comum da comunidade.

Sintomático desta potencial realidade é que a adopção dos princípios éticos relacionados com a profissão não se limita apenas ao bem pessoal, mas também ao envolvimento a todos os níveis da organização, onde a profissão efectiva se faz, com as pessoas e não de qualquer outro modo apenas individual.

Nesta ordem de ideias, a coerência, o empenhamento, a verdade e a responsabilidade, individual e colectiva, têm sempre como objectivo integrar de forma harmoniosa os recursos humanos, técnicos e financeiros de modo a optimizar os valores pessoais e sociais.

Ou seja, parece poder depreender-se que a actividade profissional será impossível sem ética, porque é ela a base de toda a actividade económica, onde a consciência ética se torna fundamental e reconhecida como indispensável para o desenvolvimento integral do homem e das organizações (Meynaud, 1996: passim). 
A este respeito queremos sublinhar que não cabe neste texto proceder a uma reflexão aprofundada sobre a ética e a profissão. As escolhas limitam-se a dar visibilidade a alguns pontos-chave que se aplicam com grande frequência quando precisamos analisar ou ter opinião, sobre os comportamentos profissionais isto é, quando estão em jogo responsabilidades pessoais com repercussões nas organizações e na comunidade.

É neste quadro de análise que os assuntos aqui tratados virão repartidos por três pontos centrais. O primeiro, analisará o conceito e $o$ significado de ética e profissão dando especial ênfase à ética.

A condição social do homem introduz-nos no segundo ponto: a ética e a profissão - construção da realidade. Embora a ética seja única, as pessoas actuam com a sua profissão num emaranhado de relações, regras e costumes. Por isso, ser ético não é algo de abstracto uma vez que coloca a pessoa em situações concretas, na organização, segundo o papel e a função que desempenha.

Finalmente, o terceiro ponto abordará uma das questões mais actuais: passar ao lado da ética na profissão. De facto, muitas vezes, a fraqueza pessoal, as pressões empresariais e sociais, são tão fortes que nos comportamos de forma pouco ética.

Neste sentido a questão da ética assume um papel fundamental no desempenho da profissão. Ora, sucede que, tendo o profissional consciência das suas responsabilidades éticas, não ignora que $o$ profissionalismo é feito de comportamentos concretos, reais e humanos fundamentado na prática da ética apesar das dificuldades que possa encontrar.

Ora, verificando-se esta situação, o tema, além de ser actual e actuante, tem também o factor novidade e por isso nos permitimos analisá-lo, ainda que de modo sumário, esperando dar ao leitor uma visão nova da relação entre a ética e a profissão e lançar pistas susceptíveis de serem continuadas e aprofundadas no futuro.

\section{A ÉTICA E A PROFISSÃO DE MÃOS DADAS}

Antes de entrarmos propriamente na parte central do tema, a ética e a profissão, ocorre, por um lado, perguntar o que é a ética e, por outro, o que é a profissão. Compreender-se-á, portanto, que a complexidade que envolve este tema nunca se esgotará, mas acreditamos que se tornará mais perceptível ao realizarmos este trabalho.

É sabido que as definições apenas ajudam a compreender e a preparar o caminho para uma análise de maior aprofundamento. Acrescente-se, no entanto, que o nosso interesse passa mais pelo conceito de ética e por isso 
virá mais desenvolvido, que o conceito de profissão. Se aludimos a estes dois vocábulos é pela importância da relação que eles têm entre si e com este trabalho porque se prendem com a conceptualização e com o comportamento do ser humano numa perspectiva mais esclarecedora merecendo esta análise.

Vamos então procurar traçar, ainda que em termos esquemáticos, o essencial da noção de ética e profissão.

\subsection{O que é a ética}

A ética no seu sentido etimológico é uma palavra que vem do grego ethos, que, segundo Trigo (1999:225), tem duas formas. O primeiro vocábulo, êthos, refere-se ao modo de ser, ao carácter, à realidade interior de donde provêm os actos humanos.

O segundo vocábulo, éthos, indica os costumes, os hábitos ou o agir habitual; actos concretos que indicam e realizam o modo de ser implantado na pessoa ${ }^{2}$.

Por seu turno, na operacionalização do conceito de ética não podemos prescindir da moral, pois não podemos ficar ao nível da abstracção, há que passar desta para a prática. Neste sentido, a moral não pode ficar privada da ética. Enfatizando, poder-se-á dizer que a moral aparece mais ou menos como institucionalização da ética.

Embora as palavras ética e moral remetam para a mesma realidade e, sejam por alguns consideradas sinónimos (Argandoña, 1994:10), os dicionários apresentam uma certa distinção. A ética investiga a fundamentação do agir, os princípios e valores, a dimensão da interioridade dos actos, aquilo que é mais pessoal. A moral indica acções e normas concretas, é a aplicação dos costumes, dos hábitos e das regras daquilo que foi objecto da ética.

Carlo Maria Martini (1993:9-11) vai mais longe e consagra quatro significados particulares à palavra ética:

1) A palavra ethos, que faz alusão, normalmente, àquilo que se costuma fazer, o modo como determinada pessoa ou a sociedade costume social - se comportam.

2) Ética, para os Gregos, significa uma sociedade bem ordenada, uma boa sociedade. Indica os comportamentos que numa sociedade, na sua sabedoria e experiência, considera positivos para a paz e a ordem social; para o progresso dos cidadãos e para o aumento do bem-estar de todos. Tais comportamentos são precisamente "éticos", ou seja, eticamente honestos.

3) Em terceiro lugar, a palavra ética é usada em sentido absoluto: ético não é apenas aquilo que se costuma fazer numa boa sociedade, mas sobretudo aquilo que é bom em si mesmo; o que deve ser feito ou evitado, 
independentemente das vantagens pessoais ou sociais que daí possam provir, o que é digno do homem ou o que se lhe opõe, o que não se pode discutir nem transigir.

4) Um quarto significado é o da ética como reflexão filosófica, sobre os comportamentos humanos e sobre o seu sentido último, onde a existência de comportamentos superiores não tem preço porque ultrapassa o prazer, o lucro e o interesse de qualquer motivação.

Como se infere do que se acaba de expor, podemos então dizer que a ética é o estudo filosófico, explicativo dos factos morais, os quais são apreciações éticas, preceitos, normas, atitudes, manifestações de consciência (Trigo, 1999:267). Os objectos da ética são os actos humanos, não apenas na sua descrição, mas na explicação da sua valorização e comportamento.

Assim, a ética pretende estudar em profundidade o ser e o sentido das normas morais, isto é, explicar o bem moral e as suas características. A ética é, portanto, a ciência da moral e a arte de dirigir a conduta. De uma forma geral, pode-se dizer que a ética é o conjunto de permissões e de interdições que têm um enorme valor na vida dos indivíduos e onde estes se inspiram para guiar a sua conduta. Na prática, como nos diz Brugger (1969: passim), a ética orienta o homem na realização dos seus fins, enquanto a moral dá a conhecer as regras aplicadas ao acto a ser cumprido.

A título de complementaridade mencionamos aqui outro conceito associado à ética e à moral que é o de deontologia. Deontologia, do grego, deon, dever, e logia - conhecimento -. A tónica da deontologia assenta numa ciência dos deveres, do que é justo e conveniente que os homens façam, do valor a que visa e do dever ou normas que dirigem o comportamento humano (Avila, 1969).

Há, portanto, uma estreita ligação da deontologia com a ética e a moral, embora seja considerada como uma ética aplicada, e restrita a um sector do comportamento humano, isto é, comportamento típico, apresentado pelo homem, quando exerce determinada profissão.

Vale a pena referir que é inegável a singularidade de cada um destes conceitos - ética, moral, deontologia -, todavia, é necessário compreendê-los num processo dinâmico onde cada um, com as suas próprias funções, os seus conteúdos específicos, intervêm conjuntamente nas relações básicas da acção pessoal, humana e social, nas actividades intelectuais e operativas do indivíduo, do inventor, do gestor, do empresário, do trabalhador, seja ele qual for, numa palavra, do profissional.

Por isso, a intervenção não é específica de uma profissão, mas a sua actuação faz parte de todo um sistema ambiental complexo onde se coloca a relação. 
São conceitos dependentes uns dos outros, que se fundamentam em valores. Esta palavra valor, do latim valore, que quer dizer ser forte, veio da economia e refere-se ao uso e permutas de coisas, são ideias que o homem introduz no real.

Por isso, os valores podem ser de satisfação, valores espirituais, culturais, de utilidade pessoal e social. Podem ser valores éticos de que só as pessoas são portadoras, que têm suportes reais, objectivos, com carácter de exigência imperativa e são universais (Avila, cit: passim).

Os valores constituem normas ou critérios que afectam esferas da nossa actividade e da nossa conduta humana. Portanto, têm um carácter normativo, oriundo das leis essenciais do ser. Os valores não sendo metas nem objectivos, no entanto, influenciam o indivíduo ou o grupo na escolha das suas decisões, conferindo um preço a determinados actos ou ideias (Idem).

Uma das principais notas caracterizadoras da ética, assinaladas por Rego, Moreira e Sarrico (2003), e que não podemos ignorar, é o facto da ética ter sempre no centro a pessoa humana, nas suas dignidade e igualdade fundamentais, no seu direito à realização e à felicidade, na sua vocação comunitária, que lhe dá o direito e o dever de ser protagonista no aperfeiçoamento da sociedade em que se insere.

Com efeito, compreende-se deste modo, as razões pelas quais a ética se tornou uma questão central do nosso tempo e condição do futuro.

\subsection{Existe uma ética da profissão?}

Todos os contributos que tratam esta questão, na sua maioria, atribuem à palavra profissão dois significados distintos ${ }^{3}$ :

1) Em sentido lato, a profissão é sinónimo de ofício, de um emprego, de uma actividade da qual o indivíduo pode tirar os seus meios de subsistência. Indica, também, o conjunto das pessoas que exercem as mesmas actividades no processo de produção de um bem ou de um serviço, pressupondo sempre um certo tipo de conhecimentos, criatividade ou habilidade para determinado trabalho (Teulings, 1973:307; Reimão, 2002:1397).

Cada profissão abrange um estatuto a que se ligam mais ou menos o prestígio e o poder, posições que se podem caracterizar com efeitos positivos, quando há um comportamento adequado, ou pelo contrário negativos, quando o prestígio e o poder são utilizados para fins pouco éticos e transparentes, trazendo problemas que a breve prazo afectam a empresa ou a organização e, a médio prazo, o próprio indivíduo que transgride através das atitudes e comportamentos não conformes com a ética. 
2) Em sentido restrito, a profissão é um ofício que desfruta de condições de exercício prestigiosas a todos os níveis na sociedade. $\mathrm{O}$ modelo das profissões liberais foi e contínua a ser o exemplo mais clássico. Esta distinção baseia-se mais numa divisão acentuada entre trabalho manual e trabalho intelectual que é posta em causa por certas formas de divisão do trabalho caracterizadas pelos critérios de responsabilidade e condenação a todos os níveis do processo de produção (Teulings, 1973: 307 e ss; Reimão, 2002:1397).

Posto isto, a essência da profissão é constituída pelo exercício de um tipo de trabalho específico, que integra fundamentalmente um posto de trabalho e uma função, onde é ditado um certo comportamento ético específico para o desempenho daquele trabalho. Por conseguinte, há uma relação muito forte entre a ética e a profissão.

O trabalho abrange todas ou quase todas as actividades humanas ${ }^{4}$; é uma actividade orientada para um fim, que exige compromisso, esforço e doação. Nas palavras de Moore (Reimão, Apud. cit:1398), o trabalho tem implicação no sistema económico e social, sendo percebido como uma ocupação individual que cada um desempenha na comunidade. Assim, o trabalho é importante quer para o indivíduo quer para a comunidade.

O posto de trabalho é um lugar, uma posição. Corresponde a um papel que é fixado e comporta ordens, instruções em relação à colocação atribuída ou escolhida ${ }^{5}$. Por um lado, o posto de trabalho relaciona-se com as tarefas, os objectivos, em relação à organização interna ou à estrutura do sistema ${ }^{6}$. Por outro lado, em qualquer profissão existe um objectivo a atingir, para cuja realização os postos de trabalho contribuem. Para tal, é preciso identificar as funções que o posto desempenha num conjunto específico mais amplo para se atingirem os objectivos da respectiva profissão.

Neste domínio, a ética desenvolveu-se a partir de um conjunto de preceitos que regem os julgamentos, as acções e as atitudes no contexto de uma teoria elaborada a partir de normas que servem de guia para distinguir os comportamentos humanos bons ou maus e de um sistema de valores segundo o qual os efeitos destes comportamentos são também julgados bons ou maus na profissão.

É por isso que a ética tem por base o critério do maior bem para a pessoa e para a sociedade como um todo. O ser humano tem um compromisso com os seus semelhantes, conduzindo à harmonia do grupo profissional $^{7}$. A ética na profissão incorre numa prática de compensações que facilitam e solidificam os laços que são de valor incalculável para a pessoa que a pratica e para a empresa onde exerce a profissão.

A prática da ética na profissão insere-se no rol dos deveres relativos à responsabilidade que cada um tem no seu trabalho. A ética não é enganosa nem abusiva, não induz a erro. Por isso, ferir a ética significa 
violar a lei dos deveres profissionais, não cumprir os compromissos assumidos por escrito ou verbalmente para com a profissão.

Portanto, a necessidade de agir em conformidade com a ética diz respeito a cada indivíduo, a cada grupo profissional com características específicas e aos grupos na sociedade em geral.

\section{A ÉTICA E A PROFISSÃO - CONSTRUÇÃO DA REALIDADE}

As considerações que fizemos no ponto anterior ajudam-nos, certamente, a olhar para a ética na profissão de forma diferente, levando-nos a opções na vida profissional com maior autenticidade e possibilidade de respostas mais conscientes e reconhecidas universalmente. "A ética é norma de comportamento humano e este devese tornar universal" (Megale, 1989:169).

A opção por uma ética na profissão não deveria, nem pode derivar, consciente ou inconscientemente, de uma situação de vazio que é preciso preencher. Pelo contrário, ela deve derivar de uma vontade e autêntica conformidade entre pensamento e comportamento profissional.

Não será autêntico uma pessoa pensar de um modo e agir de outro. Esta consciência está essencialmente ligada à capacidade de relação objectiva do sujeito entre o que pensa e o que decide fazer. Isto é questão de coerência e de justiça. "A ética é o que de mais justo existe" (Megale, 1989:169).

Daqui resulta fundamental que quem assume a profissão na sua essência ética adquira experiências activas, relacionando cada uma consigo mesma, com todo o seu eu, crescendo na profissão e nas relações profissionais, garantindo uma identidade que lhe é própria e uma contínua estabilidade profissional.

Por conseguinte, o equilíbrio fundamental, está em continuar a desempenhar uma profissão em nome da verdade, do entusiasmo, de pretensões positivas, ausentando indiferenças, acomodamentos que se tornam prejudiciais para si, para a própria profissão e, sem dúvida, para o ambiente de trabalho. Como refere Levinas (1982): "a ética é infinita". Detenhamo-nos, então, um pouco mais no papel da ética na profissão.

\subsection{Exigências éticas na profissão}

As exigências da prática profissional nunca poderão separar-se da ética, e dos códigos deontológicos da profissão, pois poder-se-á dizer que esta relação é um bem pessoal, mas também uma arte do bem comum para todos (Kitson e Campbell, 1996: 13). 
A ética profissional insere-se na ética social, ou seja, na ciência das normas relativas à actuação moral, ordenada dentro das normas dos quadros sociais. Difere da ética individual ou ciência relativa às normas de acção individual como tal. A profissão exige determinados comportamentos que se dirigem por normas específicas. Há, portanto, uma moral e uma deontologia profissional.

Moreira, ao discutir a introdução, ou não, de um código ético nas empresas, diz que "a imposição de códigos de conduta só por si seria inútil, não garante que as empresas sejam éticas, isso só se consegue se as pessoas que as integram forem íntegras, ou seja, possuidoras das virtudes morais. ... julgamos as empresas e os seus responsáveis pelas suas acções, não por piedosas declarações de intenções" (Moreira, Apud, 1999: 67).

Esta problemática prende-se com a própria natureza da concepção de ética, entendida, como podemos acentuar na reconstituição de conjuntos, de preceitos e leis que regem as acções e as atitudes no âmbito da moralidade.

No fundo, trata-se de partir de normas que servem de guia para distinguir os comportamentos bons ou maus de um sistema de valores, a partir do qual os efeitos destes comportamentos em geral são também julgados bons ou maus, em particular os comportamentos que se relacionam com a profissão.

Existe uma exigência que passa por uma conformação com a ética que diz respeito não só à pessoa, mas a cada um dos grupos da sociedade, nos quais os indivíduos estão incluídos profissional e socialmente. Segundo Moreira, um profissional pode ser perigosíssimo se o seu nível ético, por desconhecimento ou má fé, for reduzido (1999: 69).

A ética coloca-nos face à existência de uma relação de convergência entre as próprias escolhas na profissão, que envolvem todo o nosso ser, a nossa mente, a nossa acção, provocando um dinamismo de concentração positiva incontornável entre a ética e a profissão. Por isso, a ética e a profissão, duas palavras que se entrecruzam na vida profissional, sublinham, por um lado, uma grande liberdade de consciência ${ }^{8}$ e, por outro, a construção da identidade pessoal, virá a ser o objecto reconhecido e reflectido no exercício da profissão.

Ora, a ética não se prende apenas com a competência requerida para o exercício e desempenho da profissão, há objectivos, inerências profundas, que assentam em dimensões valorativas, de responsabilidade, requeridas para o perfil profissional. É que, às vezes, pensa-se que os conhecimentos superam o conjunto completo das acções realizadas, da finalidade, da relação entre as pessoas que integram a organização.

Um dos dilemas éticos na profissão é a responsabilidade nas relações laborais, por isso não admira que os autores Kitson e Campbell acentuem 
a importância da ética ao apontarem-na como um instrumento de ancoragem nas organizações (1996: 238).

É, pois, fundamental a perceptibilidade do conjunto e a coerência entre pensamento e comportamento ético para a realização do objectivo organizacional.

Para Cassiano Reimão (cit.:1400): “As relações no exercício profissional e na vida, em geral, dependem da extensão em que o indivíduo encontra saídas adequadas para as suas aptidões, interesses, traços de personalidade e valores ..." E continua mais a diante: "na gestão participativa há muito mais confiança no grupo de trabalho nas tomadas de decisão ... o que conduz ao envolvimento na organização"

Nós acrescentamos que o desempenho, o envolvimento na organização, a acção profissional só são realizáveis e satisfatórias para o conjunto organizacional se cada indivíduo se munir de uma ética pessoal com repercussões directas na própria profissão e indirectas na organização .

Sendo assim, a prática profissional em todos os tipos e desenvolvimentos da profissão exige quotidianamente tomadas de decisão éticas e morais. A conduta humana e moral nas organizações é questão de ética profissional e passa pela honestidade dos seus elementos (Kitson e Campbell: 1996: 97-225).

Mesmo sabendo que os dilemas éticos estão a aumentar de complexidade, à medida que a ciência e os conhecimentos intervêm no desempenho da profissão, que envolve relações directas com os seres humanos e com a sociedade cada vez mais exigente, torna-se urgente tecer considerações que impliquem sempre compromissos com os direitos humanos. $\mathrm{O}$ ambiente de trabalho do indivíduo afecta o seu desenvolvimento e se os princípios éticos não estiverem presentes, o trabalho revelar-se-á, com efeito, muito pouco eficaz. Isto quer dizer que não podemos ignorar as responsabilidades que temos na profissão, seja ela de que tipo for, independente ou dependente, liberal ou outra.

Cada vez mais, as empresas de diversos sectores, reconhecem que o debate sobre a ética é uma oportunidade para que as organizações empresariais levem a cabo os seu negócios, tendo como objectivo competir com êxito dentro de uma economia global competitiva e complexa (Tierney, 1999:13). Ora, as empresas não existem sem pessoas e são estas que as valorizam e dignificam.

Em síntese, podemos dizer que qualquer profissão levanta questões morais e éticas que podem ser favoráveis ou desfavoráveis no grupo, favorecendo ou lesando os direitos fundamentais das pessoas.

A ética coloca problemas que decorrem das exigências morais que podem entrar em conflito entre as pessoas nas organizações. Existe um certo limite que todo e qualquer profissional não deve ultrapassar. $\mathrm{O}$ 
desrespeito pelas pessoas, pelo direito de viver digna e humanamente, causando prejuízos aos demais é imoral e eticamente inaceitável para as relações na profissão.

Em suma, as exigências da ética não são apenas assunto de palavras, envolvem comportamentos que se radicam necessariamente na moralidade e em valores. Muitos dos problemas fluem directamente da ausência de valores e de princípios morais, onde certos comportamentos são inaceitáveis.

É assim que as exigências da ética na profissão, assentam sobre qualidades atitudinais e valorativas que resultam da responsabilidade, honestidade, autenticidade e do sentido de justiça. Estas e muitas outras características da ética permitem certos comportamentos, padrões de conduta, que fundamentam as escolhas das relações profissionais.

Finalmente, podemos evidenciar que a consistência da ética na profissão radica essencialmente na consciência e se concretiza nos critérios da justiça. Não é por acaso que a crescente atenção em relação aos temas da ética é sobretudo alimentada por problemas concretos de "justiça", propostos pelas formas de experiências com referência à ética dos negócios e das profissões (Kenneth e Peale, 1988: 37 e ss).

Uma ética profissional de tal género contribui para o desenvolvimento da própria consciência "moral" do profissional; daquela consciência que exige dele, não apenas lesar os direitos dos outros, mas viver o próprio empenhamento profissional, importante para a própria vida da pessoa.

É óbvio que a profissão de uma pessoa, mesmo qualificada, actualizada, se é necessária, não é suficiente. São precisas autênticas regras éticas para viver de modo objectivo e se afirmar na profissão com a sua própria condição humana.

\subsection{Perseverar no caminho da ética}

Hoje precisamos de personalidades fortes e honestas em todos os campos da vida social, económica, política, etc., personalidades com ética. Muitas pessoas estão à altura de responder quando as necessidades de sucesso se impõem, quando recebem estímulos para agir num sério ethos profissional e social.

Porém, alguns, esvaziam a nossa inteligência, estupidificam-nos, esmagam-nos através de processos inaceitáveis. A coragem, a força dos valores mais altos, leva-nos a perseverar, a ir à procura daquilo que nos eleva e não daquilo que nos diminui. Agir em conformidade com os valores (Kenneth e Peale, 1988: 46). Depois procuramos uma ancoragem forte, segura e sólida numa consciência que não se deixa manobrar por influências nada saudáveis nem gratificantes para o desempenho da profissão. 
A ética tem como referência a dignidade humana que muitas vezes vem instrumentalizada e manipulada, perdendo a pessoa a sua identidade pessoal e social. O problema é: se as pessoas se vendem, ou não se vendem, a ideias, ou a benefícios que nada têm a ver com a ética ${ }^{10}$. Por isso, é preciso uma orientação que se abra a princípios potencialmente positivos que diga respeito à consciencialização e sensibilidade, essenciais na profissão.

A questão da ética profissional é um fenómeno multifactorial que leva à interiorização de um conjunto de valores morais e sociais que disciplinam e padronizam os comportamentos das pessoas nas organizações. Mas, por outro lado, leva à interiorização de um conjunto de expectativas racionais que implicam contrapartidas padronizadas num sistema de recompensas e de status.

Se pensarmos que a grande maioria dos membros de uma empresa passa a sua vida nos locais de trabalho, nessas condições não é possível continuar a omitir comportamentos éticos como sendo uma realidade que está fora da organização. O seu caminho terá de trilhar sendas saudáveis e perseverar nelas. Deve pautar-se sempre por uma linha de rigor, de verdade e de justiça, e não o contrário, embora por vezes os combates se tornem difíceis de gerir.

Mas, para arredar muitas atitudes comportamentais não éticas na profissão o empenhamento é de todos, não se pode pretender que um simples funcionário imprima à sua profissão valores morais e éticos, quando quem tem o poder não altera o seu comportamento menos ético.

Se não se reconhecer o trabalho, o mérito, pensamos que todo o mundo está contra nós. Aliás, uma empresa dispõe de diversos meios para encorajar e favorecer as posições éticas e morais dos seus elementos. É importante criar na organização um tipo de envolvimento que favoreça as tomadas de decisão ética e uma boa moral. Isto só será possível quando se adoptarem condutas honestas, quando se ouvir a voz da consciência, quando não se vender a qualquer preço.

Como refere Kenneth e Peale, "Os dirigentes devem criar um envolvimento positivo fundado sobre valores ... Exigem-se chefes com princípios éticos elevados" (1988: 90,91).

A ética do líder, da autoridade, é importante para a qualidade da organização (Aguilar, 1994: 117). As exigências são estabelecidas para todos e não só para alguns.

Não podemos deixar de ter em conta que é necessário que quem domina os grupos profissionais abdique de certas prerrogativas e não faça presidir às suas estratégias objectivos pessoais e irresponsabilidades, esquecendo empresas, pessoas, valores, princípios, critérios de rigor na aplicação de normas. Numa palavra, que não resiste à ética que se impõe como potencial da convivência humana no local de trabalho. 
Só a partir desta convivência a motivação profissional será conseguida não só para si próprio, mas também, com melhores resultados para a organização. De facto, a ausência de motivação é uma ruptura entre o indivíduo e a sua profissão. O trabalho não pode ser afectado, pondo em causa a identidade e a consciência do trabalhador, não lhe proporcionando satisfação; alienado, sente-se frustrado.

A ética incita as pessoas a continuar numa tenacidade, e até teimosia, permanente e duradoura, porque ela é muito útil, universal e, por isso, o que é precioso para o desenvolvimento, crescimento e bem das pessoas não se deve desperdiçar ou deitar fora.

Só assim se compreende que a ética e a profissão sempre estiveram juntas, cada vez mais se reconhece que são altamente úteis as relações entre si, e por isso andam sempre de mãos dadas (Moreira, 1999). Portanto, a ética é uma exigência do ser humano, pois ensina-nos como passar do ser ao dever ser na profissão, do homem como é ao homem como deve ser.

$\mathrm{Na}$ verdade, hoje, no mundo profissional, a condução da empresa fundada em valores morais tem a ética como o primeiro elemento de qualidade de vida e do sucesso da empresa. Quando as pessoas se sentem maltratadas, perdem todo o respeito para com a organização e todos se saturam do seu trabalho, revelando-se o desinteresse, a falta de motivação, o que torna a empresa pouco eficiente e eficaz.

Deste modo, compreende-se que é preciso continuar perseverante, manter-se igual a si mesmo, firme e invariável, seja qual for a posição que se tem na profissão, na empresa, num dado momento.

Para concluir este ponto sobre a perseverança na ética, não resistimos a fazer nossas as palavras de Winston Churchill, retiradas da obra de Kenneth e Peale (1993: 59,60), ao referirem-se a um dos cinco princípios da ética: a persistência ${ }^{11}$ :

"Nunca me hei-de esquecer do discurso que Winston Churchill fez, já no fim da vida, na escola preparatória que tinha frequentado em Inglaterra. O director disse aos alunos: "Este é um momento histórico. Winston Churchill é o maior orador de língua inglesa. Tomem nota de tudo o que ele disser. Vai fazer um discurso inesquecível". "Quando se preparava para fazer o discurso, Churchill espreitou por cima dos óculos e disse: Nunca! Nunca! Nunca! Nunca Desistam!”.

\section{PASSAR AO LADO DA ÉTICA NA PROFISSÃO}

Certamente, não será em vão alertar que vivemos demasiado virados para nós próprios, obcecados por um eu que cultiva na nossa vida, nas nossas acções, o conceito esvaziado de verdade e responsabilidade. 
Alimentamo-nos do que se vende, o que é bem pago, o que é mais fácil, o egoísmo e o individualismo, empobrecendo, defraudando os interesses da ética profissional. Doença muito comum nos nossos dias, esvaziando de significado, do interesse comum, a empresa, a organização e a profissão, tirando-se partido em proveito próprio, sem se preocupar com o que isso possa representar para os demais.

No entanto, trata-se de um egoísmo bastante refinado, inadmissível, sobretudo para os princípios básicos que fundamentam a profissão. Este sentimento indica que o homem é lobo do homem - Homo homini lupus -, onde o egoísmo supera a ética humana e nos esquecemos com muita frequência do dever ser e não apenas do dever ter. É por isso que muitas vezes por certas conveniências passamos ao lado da ética na profissão. Numa simples expressão de Alberoni (1994: passim), abandonamos valores fundamentais.

\subsection{As causas}

Nas sociedades de hoje, onde prevalecem o consumismo, o individualismo, o economicismo, a competitividade desonesta, o poder, o utilitarismo, onde se pensa no poder, na riqueza pessoal, esta questão da ética na profissão é cada vez mais actual, mas também geradora de conflitos, pelo que não admira que um grande número de pessoas nas diversas áreas do saber - ciências médicas, teológicas, sociais e humanas - se dediquem à importância que a ética tem na dinâmica e acção laboral e empresarial (Kitson e Campbell, 1996: 28).

Não seria inoportuno interrogarmo-nos como é posta em prática a ética na profissão, pois, se não a exercitamos, definha-se, morre e esquecemo-nos que ela existe.

Muitas vezes, somos nós próprios, na nossa profissão, a furtarmo-nos a um bem tão precioso como é a ética no relacionamento com os outros. Contabilizamos as nossas expectativas sempre no intuito de obter ou reaver, sem qualquer forma desinteressada, o bem próprio. Cultivamos um certo padrão de importância e pretendemos um trato especial, pensamos que a ética é um papel a executar não por nós, mas pelos outros.

É isto que acontece de forma tão disfarçada, que nem tomamos verdadeira consciência quando recorremos a subterfúgios, para justificarmos e subtilizar a ética que praticamos na profissão. Esta aparece desmedidamente destituída de códigos éticos, morais e deontológicos específicos porque se usam pretextos que reflectem atenção excessiva à própria pessoa, predominando os interesses pessoais.

A pessoa habituada a mentir na família e aos seus amigos, dificilmente será sincero na vida profissional. Muitas vezes, para ganhar dinheiro, para 
conquistar poder está disposto a falsificar documentos, a faltar à palavra dada e é provável que pratique muitas outras irregularidades com o mesmo fim. Estes comportamentos para atingir os fins sem olhar aos meios são reprováveis pela prática da ética.

Assim, passar ao lado da ética é património dos negócios, das empresas, das profissões, das pessoas para se obterem benefícios próprios $^{12}$.

Vivemos num ambiente competitivo, numa aldeia global, por isso temos de reflectir e reconhecer que os conflitos éticos são uma realidade nas organizações, mas que trazem implicações menos boas nas decisões e nos resultados (Cortina, 1994).

A cultura nas organizações é muitas vezes demasiado resistente. Como evidencia Drummond e Bain: "A conexão entre ética e cultura na organização está em crise" (1994: 39,40). Na verdade, a mudança cultural é essencial, mas muito difícil de realizar, no que respeita à moral e à ética.

As organizações de sucesso são, de facto, aquelas nas quais se pratica uma moral excelente, não tenhamos dúvida. As que fazem mudança, a nível dos comportamentos éticos, tiram vantagem em relação às que continuam incapazes de adaptação à mudança.

Diversas influências podem assim afectar a nossa ética, porque pressões podem colocar as nossas necessidades acima das dos outros. É óbvio que, nalgumas ocasiões, esquecemo-nos desta realidade na profissão e por isso sofrem-se as consequências por esses comportanentos.

\subsection{As consequências}

A análise que acabamos de aflorar sobre as causas que nos fazem passar ao lado da ética, leva-nos a supor que a ética na profissão tem um carácter maioritariamente baseado na justiça. $\mathrm{O}$ mais importante da ética é este sentir de responsabilidade de todos.

Efectivamente, a ética é importante. Do ponto de vista pragmático, se uma decisão resulta pouco ética, se há provas de se ter causado dano a pessoas, o nosso nome aparece sempre em termos negativos com desvantagens a nível profissional.

Como nos refere Tierney (1999: 33): "Todos estamos sujeitos ao escrutínio público. Ninguém gosta de ser exposto, pondo em perigo o bom nome, ou a reputação ... perdendo benefícios".

Por vezes, trabalhamos com pessoas que não querem discutir sobre ética. Por um lado, não são capazes de ver o mérito ou as implicações positivas que possa trazer e, por outro, porque não vêem os prejuízos que porventura estão associados às práticas pouco éticas. Portanto, os custos de uma conduta pouco ética ou os benefícios que se têm pela sua prática. 
Estes factos são argumentos úteis e por isso devemos reconhecer a importância que têm mesmo existindo pessoas que o não reconheçam ${ }^{13}$.

Há muitas pessoas cuja conduta é pouco ética porque olham à sua volta e observam como muitos outros se saíram durante muitos anos. Tierney (1999:62) anuncia mesmo que muitos "citam com frequência exemplos de comportamentos detestáveis que conduzem ao êxito ... de igual forma, aqueles que tiveram êxito utilizando práticas pouco éticas podem também sair impunes".

Por conseguinte, os custos para actuar sem ética são consideráveis. Tierney (cit.:64 e ss) apresenta um conjunto, dos quais lembramos aqueles que do nosso ponto de vista parecem ser os mais relevantes.

a) A reputação e a carreira podem arruinar-se por se ignorar a ética. Às vezes pode parecer que a ética é imaterial. Todavia, a falta de ética pode prejudicar o que é material, ou seja o trabalho concreto.

b) Perda de confiança. Esta perda de confiança pode conduzir à perda de confidencialidade, a uma comunicação censurada, a uma auto-estima pobre, à falta de compromisso, à lealdade, e, por último à demissão. A confiança é essencial para o êxito das relações profissionais.

As relações constroem-se sobre convicções, na credibilidade de parte a parte, quando se acredita que se diz a verdade e se assumem compromissos.

c) Perda do bom nome. Este custo associado às condutas ou práticas pouco éticas resulta da perda de confiança. Uma boa reputação pode ser substituída por uma menos boa ou mesmo má. Quando se desfruta de uma boa reputação e esta se perde, dificilmente se readquire. Por isso, não recompensa a sua perda.

d) A ineficiencia do trabalho em equipa. A falta de confiança, pois quando se trabalha na mesma empresa, por vezes dão-se certos incidentes que fazem com que alguns se sintam incomodados com a situação. Uns começam a dar-se conta que outros são ambiciosos, que pretendem atingir o poder, o dinheiro, ascender na empresa e que farão tudo para o conseguir.

Com este procedimento surgem as dificuldades em fazer o trabalho. Poderemos questionar-nos: como se pode trabalhar juntos se um vê no outro uma ameaça? Manipula-se, oculta-se a informação e por isso não se está disponível, não se assumem riscos, não se oferecem soluções criativas. Falta motivação, o ambiente está doente.

Falta a confidencialidade, começa a diminuir o intercâmbio da informação, tanto negativa como positiva. Estabelece-se um mal-estar entre as pessoas e desconfia-se de tudo.

e) Comunicação censurada. À medida que diminui a confiança, a comunicação que é um elemento vital na organização, virá dificultada. A reputação perder-se-á à medida que a relação enfraquece. $\mathrm{O}$ outro fará 
tudo para que adquira a sua própria posição e dessa forma ascender no trabalho.

Imaginando que a pessoa em quem não se confia é o chefe, porque não foi honesto, as implicações na relação tornam-se muito mais desagradáveis e difíceis.

f) Perda de auto-estima. À medida que diminui a comunicação, também diminui a disposição para partilhar ideias, claro que nos fartamos da outra pessoa, mas também tendemos a culpar o nosso próprio juízo por não termos visto antecipadamente o que parecia óbvio.

g) Falta de compromisso. É lógico, se a auto-estima não existe, não surpreende que a eficácia das suas acções ou das suas ideias diminua o seu entusiasmo pelo trabalho. Quando não há confiança uns nos outros, gastam-se energias nos ataques uns aos outros e não se assumem compromissos.

h) A lealdade declina. Parece que não vale a pena fazer-se esforço, partilhar ideias, ser responsável, quando os trabalhos se repartem por favoritismo, nepotismo ou subornos. Às vezes esconde-se: se a organização não me dá nada porquê dar-lhe a minha lealdade?

i) A demissão. $\mathrm{O}$ director, gerente ou administrador poderá pensar e decidir que alguém deste tipo de motivação tão baixa se deve ir embora. É óbvio que, mais tarde ou mais cedo, esta pessoa tão descontente se retirará do trabalho ou optará por encontrar outro.

Mas, se não se for embora, a organização estará sempre preocupada com as mensagens e atitudes que transmite a outros membros. Tanto num caso, como no outro, é provável que desça a qualidade do serviço.

Claro que as experiências negativas por questões éticas na carreira de uma pessoa podem ter interacções futuras. A auto-estima diminui e ficam comprometidas novas relações e a insegurança manifesta-se nas relações de trabalho.

Recordo, no entanto, o facto de que muitas vezes se atribuem as questões de confiança aos princípios e às condutas pouco éticas de uma pessoa, que traz consequências para o rendimento do trabalho. Porém, outros factores afectam o rendimento. Alguns trabalhadores não são capazes, não têm vontade de trabalhar. Estas situações extremas afectam não só a sua profissão, a sua carreira, mas, também, a produtividade e o rendimento da empresa.

Mas as consequências não têm só impacto na profissão de um indivíduo num ambiente incómodo e pouco ético, alguns problemas estão também relacionados com a possível repercussão das práticas pouco éticas sobre a empresa no seu conjunto ${ }^{14}$.

Há que fazer aqui um parêntesis para dizer o seguinte: o bom nome da empresa ou a suspeita de uma actuação incorrecta, com falta de ética, pode levar a situações pouco benéficas e em muitos casos irrecuperáveis. 
Deste modo, os comportamentos éticos são uma oportunidade tanto para o trabalhador como para a própria instituição onde trabalha. É por isso que, nesta linha de pensamento, a confiança, a colaboração, a verdade e as responsabilidades mútuas permitem o êxito do trabalhador e da instituição no seu conjunto.

Todos os recursos humanos da empresa têm papel decisivo e, por isso, é bom que saibam aproveitar as suas potencialidades, assentes em valores e princípios éticos no trabalho.

Importa aceitar a nossa condição humana. Igualmente devemos aceitar a condição dos outros com os quais trabalhamos. Todas as actividades envolvem seres humanos, interacções humanas, e essa condição humana tem profundas implicações na forma como desempenhamos o nosso papel na profisssão.

Cada pessoa é um indivíduo único e cada um é um ser humano, o seu carácter afecta a forma como se comporta eticamente na profissão. Por isso, a ética questiona-nos acerca dos compromissos assumidos na profissão, na empresa e na sociedade. Obviamente que teremos que reflectir sobre estas questões da ética e tirar as respectivas conclusões.

\section{CONCLUSÃO}

A exposição sistemática da nossa reflexão teve como esqueleto os simples pontos que compõem a problemática da ética e da profissão.

Necessariamente, as repetições que fizemos sublinham a frequência de traços particulares, em função da intensidade e importância com a qual os simples aspectos são tratados e analisados.

Embora a análise seja limitada, encontramos sempre a presença de elementos constantes que mostram o background comum e que constituem as estruturas latentes próprias de qualquer realidade complexa e que se podem resumir às seguintes:

a) Interdependência entre os dois termos. A exposição mostra a diferente valência e importância da problemática em relação à ética e à profissão fazendo centrar a ideia no aspecto comportamental e atitudinal da pessoa na profissão e na sociedade.

b) Continuidade da ética. A ética apresenta-se como uma exigência da qual não se pode prescindir na vida profissional e social. Nestas vidas existem imperfeições, carências estruturais e funcionais, imprevistos da mais variada natureza e gravidade, superam-se possibilidades e respostas nas mais diversas situações. A ética continua uma exigência constante, tornando-se a grande valia nas relações profissionais.

c) $O$ valor da ética e da profissão. A resposta às várias situações, nas quais as pessoas se possam encontrar, sublinha o valor da ética e 
evidencia a função dos princípios morais que devem reger a vida profissional. Sublinha a presença de valores e ideias que orientam e justificam o próprio comportamento nas relações laborais.

Estas ideias não são qualquer coisa de utópico, mas transformam-se numa força operativa, capaz de responder a um estilo de vida saudável para as pessoas que as praticam. Combater as injustiças favorece os que as escolhem e adoptam e permitem um crescimento humano e uma convivência saudável entre as pessoas nas empresas onde trabalham.

Pelas razões descritas, e por muitas outras que ficaram por analisar, pensamos que a ética é uma afirmação de cada um, de todos no dia a dia, em qualquer grupo onde se encontrem inseridos.

Sem pretendermos dar aulas de moral, acreditamos, que no dia em que a ética fizer parte integrante do sistema, as pessoas - recursos humanos melhorarão em muito as performances das empresas, o diálogo e a cooperação, a qualidade de vida no trabalho, com consequente nível de melhoria da qualidade, da redução de desperdícios conceptuais e humanos, maior responsabilidade, melhor participação e progresso profissional e empresarial.

Na prática, de uma ética moral na vida profissional, todos colherão os seus frutos, porque quando as pessoas se vêem privadas de referências surgem comportamentos ou condutas associais ou a "anomia" usando a designação do sociólogo francês Émile Durkheim.

\section{NOTAS}

${ }^{1}$ Embora o conceito de organização não seja sinónimo de empresa, neste trabalho utilizaremos indistintamente as duas expressões como querendo dizer o mesmo. Isto porque os conceitos de ética e profissão - a base deste texto - dirigem-se ao organizador, ao gestor, ao empresário, ao trabalhador em todos os tipos e lugares de trabalho. Em segundo lugar, para não estarmos a utilizar a mesma palavra na mesma frase, ou parágrafo, tornando o texto menos elegante.

22 Estas duas acepções foram traduzidas em latim por mores que significa "costume ou costumes", maneira de agir em virtude de uma espécie de hábito. Exprime uma dimensão repetitiva dos actos habituais. Conf. Jerónimo Trigo in Enciclopédia Luso Brasileira da Cultura, p. 225,226.

${ }^{3}$ Não é nossa pretensão fazer a retrospectiva da evolução que este conceito foi sofrendo ao longo da história. Tal orientação levar-nos-ia a fazer não um trabalho de análise acerca da ética e da profissão na perspectiva mais social, e sim um trabalho histórico que não faz parte dos nossos objectivos. Seria importante, mas não foi o caminho escolhido.

${ }^{4} \mathrm{O}$ que se diferencia de alguns significados que apenas têm em conta o trabalho como aquele que é remunerado. No nosso caso o conceito é mais abrangente, refere-se a todas as actividades mesmo aquelas não remuneradas. 
${ }^{5}$ Entram nesta concepção os significados sobre os papéis e as funções no seu modo, ou tipo de aquisição nas mais diversas formas.

${ }^{6}$ Objectivamente, as qualificações humanas condicionam a selecção, promoção e todo o sistema de retribuição. Subjectivamente, outros factores que não as qualificações servem também para contrariar tais condições.

${ }^{7}$ A primeira tentativa formal de impor comportamentos éticos na empresa deve-se à Encíclica Rerum Novarum, do Papa Leão XIII. Nela foram expostos princípios éticos aplicáveis aos relacionamentos e à interacção entre a empresa e os seus empregados. Esses princípios valorizam o respeito aos direitos e à dignidade dos trabalhadores.

${ }^{8}$ Liberdade não de fazer o que nos dá real gana, nem mesmo apenas livre arbítrio, mas sim, a liberdade de poderem ser o que somos chamados a ser na própria profissão que temos.

${ }^{9} \mathrm{O}$ conceito por nós aqui analisado, coloca-se num âmbito mais vasto, não se limitando apenas à sua natureza, aos postos de trabalho, às funções, à vocação para determinada profissão, à motivação e realização profissional, onde dominam o desempenho, a eficácia, as promoções, os vencimentos que são muito importantes. É, no entanto, do nosso interesse mais o comportamento e a atitude profissional pela influência que tem nas relações laborais.

${ }^{10}$ Por exemplo, um sociólogo a trabalhar por conta de outrem pode ter a sua ética. Mas é preciso não transgredir. É preciso que a ética atravesse as organizações, mas a ética está também no interior de cada um de nós. Porém, a falta de ética pode acontecer não só no trabalho por conta de outrem, não é verdade. O mesmo sociólogo numa investigação pode ser tendencioso, falsificar dados, isso é falta de ética. Não é este o caminho correcto, não é honesto, não é transparente, não é ético. Mas não é apenas uma questão dos sociólogos, atravessa todas as profissões e todas as sociedades.

${ }^{11}$ Os autores apresentam em toda esta obra os cinco princípios: Propósito (estar bem com a vida, consigo próprio); Orgulho (sentimento de satisfação); Paciência (hoje tão difícil, mas quando somos pacientes olhamos as coisas de modo diferente, com mais optimismo); Perspectiva (capacidade de ver o que é realmente importante. A perspectiva é de certo modo o eixo em torno do qual os outros quatro princípios se guiam). Finalmente, a Persistência (honrar os compromissos assumidos - adesão contínua aos padrões éticos - necessidade de persistir para se manter fiel). "O não despegar em determinada situação para se manter na pista certa” p.59.

${ }^{12} \mathrm{O}$ mundo dos negócios mudou profundamente nas últimas décadas, a realidade é muito mais complexa. As pessoas põem poucas questões sobre a importância da ética, não há escrúpulos nos comportamentos que se tomam. Olha-se apenas à sua volta e os bens materiais são justificação para desconsiderar a ética e obter proveito próprio. De um modo geral, o fanatismo distancia a pessoa da linguagem da ética na profissão.

${ }^{13}$ A justificação para este ponto de vista, é que muitas vezes os resultados que parecem obscuros nem sempre são negativos. Algumas pessoas têm mesmo êxito e fazem negócios e dinheiro dessa forma. Por isso não reconhecem a sua utilidade. Não se pretende dizer que todas as pessoas são por natureza desonestos, supomos que não.

${ }^{14}$ Basta recordar qual o preço da conduta pouco ética de algumas campanhas, quando essa conduta é do domínio público. Não há dúvida que algumas pagaram e pagam um preço muito grande, quando a sua conduta se revela sem ética. Algumas pessoas optaram pelo suicídio para não enfrentarem a humilhação pública, o juízo 
popular. Outras perderam o futuro profissional. Alguns dirigentes pagam pelos seus próprios erros e pelos da empresa.

\section{BIBLIOGRAFIA}

AGUILAR, Francis J. (1994), Managing Corporate Ethics, New York; Oxford: Oxford University Press.

ALBERONI, Francesco (1994), Valores, Venda Nova: Bertrand.

ALVES, José Manuel Rodrigues (1997), "Poder e ética na formação de professores: um contributo psicanalítico" in Percursos de formação e desenvolvimento profissional, Colecção CIDINE, no 3, Porto: Porto Editora Lda. p.139-60.

ARGANDOÑA, Antonio Ramiz (1994), La ética en la empresa, Madrid: Instituto de Estudios Económicos.

AVILA, Fernando Bastos (1969), "Deontologia" in Dicionário de Filosofia, São Paulo: Herder.

BRUGGER, Walter (1969), "Ética” in Dicionário de Filosofia, São Paulo: Herder.

CORTINA, Adela (1994), Ética de la Empresa: Claves para uma nueva cultura empresarial, Madrid: Ed. Trotta.

DRUMMOND, John e BAIN, Bill (ed.), (1994), Managing Business ethics, Oxford: Butterworth.

FREITAS, Manuel (1967), "Consciência" in Enciclopedia Luso - Brasileira de Cultura, Vol. V, Lisboa: Verbo, p. 1424-28.

GIL, Marta López e Delgado Liliana (1996), De camino a una ética empresarial, Buenos Aires: Biblos.

KENNETH, Blanchard e PEALE, Norman Vicent (1988), Éthique et management, Paris: Les Éditions d Organisation.

KENNETH, Blanchard e PEALE, Norman Vicent (1993), O poder da ética, Lisboa: Difusão Cultural.

KITSON, Alan e CAMPPBELL, Robert (1996), The Ethical Organisation, London: MacMillan.

LEVINAS, E. (1982), Éthique et infini, Paris: Arthèmme Fayard.

MARTINI, Carlo Maria (1993), Viaggio nel vocabolario dell etica, Milano: PIEMME SPA.

MEGALE, Januário Francisco (1989), Introdução às ciências sociais, São Paulo: Atlas S.A.

MEYNAUD, Hélène-Yvonne (org), (1996), «Les enjeux éthiques dans les organisations modernes» in Les sciences sociales et l'entreprise, Paris: Dècouvert, p. 336-357.

MOREIRA, José Manuel (1996), Ética, Economia e Política, Porto: Lello \& Irmãos Editores.

MOREIRA, José Manuel (1999), A Contas com a Ética Empresarial, Cascais: Principia.

PINTO, José Rui da Costa ( $\left.{ }^{3} 1990\right)$, Questões actuais da ética, Braga: Editorial A O.

PIRES, Celestino (1976), "Verdade", in Enciclopédia Luso - Brasileira de Cultura, Vol. XVIII, Lisboa: Verbo, p. 903-10.

REGO, Arménio; MOREIRA, José Manuel e SARRICO, Cláudia (2003), Gestão Ética e Responsabilidade Social das Empresas, S. João do Estoril: Principia. 
REIMÃO, Cassiano (2002), "Profissão", in Enciclopedia Luso - Brasileira da Cultura, Vol. 23, Edição Séc. XXI, Lisboa/São Paulo: Verbo, p. 1397-405.

TEULINGS, W. M. (1973), "La position de classe des travailleurs scientifiques», in Sociologie du Travail, ${ }^{\circ}$ 3, p. 307-20.

TIERNEY, Elizabeth P. (1999), Ética empresarial, Madrid: Griker \& Asociados.

TRIGO, Jerónimo (1999), "Ética", in Enciclopédia Luso - Brasileira de Cultura, Vol. XI, Edição Século XXI, Lisboa/São Paulo: Editorial Verbo, p. 225-28. 